Sensors and Transducers 


\section{Other Macmillan titles of related interest}

B. Allen, Analogue Electronics for Higher Studies

W.A. Atherton, From Compass to Computer

J.C. Cluley, Transistors for Microprocessor Systems

Donard de Cogan, Solid State Devices - A Quantum Physics Approach

C.W. Davidson, Transmission Lines for Communications, second edition

M.E. Goodge, Analog Electronics

B.A. Gregory, An Introduction to Electrical Instrumentation and Measurement Systems, second edition

Robin Holland, Microcomputer Fault-finding and Design, second edition

Paul A. Lynn, An Introduction to the Analysis and Processing of Signals, third edition

R.J. Mitchell, Microprocessor Systems - An Introduction

Noel M. Morris, Electrical Circuit Analysis and Design

M.S. Nixon, Introductory Digital Design

P. Silvester, Electric Circuits

L.A.A. Warnes, Electronic Materials

B.W. Williams, Power Electronics - Devices, Drivers, Applications and Passive

Components, second edition

New Electronics Series

Series Editor: Paul A. Lynn

G.J. Awcock and R. Thomas, Applied Image Processing

Rodney F.W. Coates, Underwater Acoustic Systems

M.D. Edwards, Automatic Logic Synthesis Techniques for Digital Systems

Peter J. Fish, Electronic Noise and Low Noise Design

W. Forsythe and R.M. Goodall, Digital Control

C.G. Guy, Data Communications for Engineers

Paul A. Lynn, Digital Signals, Processors and Noise

Paul A. Lynn, Radar Systems

R.C.V. Macario, Cellular Radio - Principles and Design

A.F. Murray and H.M. Reekie, Integrated Circuit Design

F.J. Owens, Signal Processing of Speech

Dennis N. Pim, Television and Teletext

M. Richharia, Satellite Communications Systems - Design Principles

M.J.N. Sibley, Optical Communications, second edition

P.M. Taylor, Robotic Control

G.S. Virk, Digital Computer Control Systems

Allan Waters, Active Filter Design 


\title{
Sensors and Transducers
}

Characteristics, Applications, Instrumentation, Interfacing

\author{
M.J. Usher and D.A. Keating
}

Department of Cybernetics

University of Reading

Second Edition

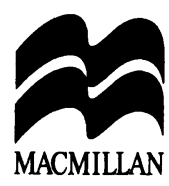


All rights reserved. No reproduction, copy or transmission of this publication may be made without written permission.

No paragraph of this publication may be reproduced, copied or transmitted save with written permission or in accordance with the provisions of the Copyright, Designs and Patents Act 1988, or under the terms of any licence permitting limited copying issued by the Copyright Licensing Agency, 90 Tottenham Court Road, London W1P 9HE

Any person who does any unauthorised act in relation to this publication may be liable to criminal prosecution and civil claims for damages.

First edition 1985

Reprinted 1990

Second edition 1996

Published by

MACMILLAN PRESS LTD

Houndmills, Basingstoke, Hampshire RG21 6XS and London

Companies and representatives throughout the world

ISBN 978-0-333-60487-8 ISBN 978-1-349-13345-1 (eBook)

DOI 10.1007/978-1-349-13345-1

A catalogue record for this book is available from the British Library 


\section{Contents}

Preface

Acknowledgements

vii

1 Introduction 1

1.1 Analogue and digital quantities 1

1.2 Classification of sensing devices 2

1.3 Sensors, transducers and actuators 3

1.4 Types of transducer 4

1.5 Transducer parameters 6

1.6 Measurement systems 9

1.7 Exercises 11

2 Analogies between Systems 12

$\begin{array}{ll}2.1 \text { Analogies } & 12\end{array}$

2.2 Mechanical and electrical systems 12

$\begin{array}{lll}2.3 & \text { Fluid systems } & 16\end{array}$

$\begin{array}{lll}2.4 & \text { Thermal systems } & 17\end{array}$

2.5 Other systems: radiant, magnetic, chemical 18

2.6 Exercises 20

3 Physical Effects available for Use in Transducers 21

3.1 Representation of transducers 21

3.2 Self-generators 23

$\begin{array}{llr}3.3 & \text { Modulators } & 29\end{array}$

$\begin{array}{lll}3.4 & \text { Modifiers } & 37\end{array}$

3.5 Exercises 39

4 Transducer Bridges and Amplifiers 40

4.1 Transducer bridges 40

4.2 Transducer amplifiers 43

4.3 Practical operational amplifier characteristics 46

4.4 Exercises $\quad 50$

5 Transducers for Length 52

5.1 Classification of length transducers 52

5.2 Displacement transducers 52

5.3 Velocity transducers $\quad 71$

5.4 Strain transducers $\quad 73$

$\begin{array}{lll}5.5 & \text { Exercises } & 78\end{array}$ 
6 Transducers for Temperature 83

6.1 Scale of temperature $\quad 83$

6.2 Temperature transducers $\quad 83$

$\begin{array}{ll}6.3 \text { Exercises } & 90\end{array}$

7 Transducers for Light 93

$\begin{array}{lll}7.1 & \text { Light and its properties } & 93\end{array}$

$\begin{array}{lll}7.2 & \text { Classification of photodetectors } & 94\end{array}$

$\begin{array}{lll}7.3 & \text { Thermal photodetectors } & 95\end{array}$

$\begin{array}{llr}7.4 & \text { Photon detectors } & 99\end{array}$

$\begin{array}{ll}7.5 \text { Exercises } & 107\end{array}$

8 Other Transducers $\quad 109$

8.1 Acceleration transducers 109

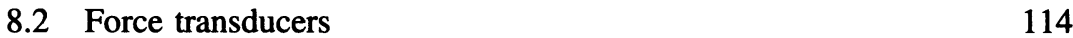

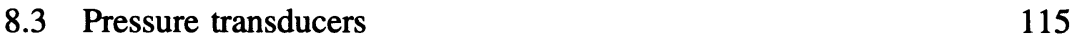

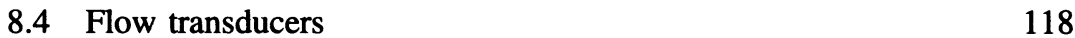

$\begin{array}{ll}\text { 8.5 Microphones } & 126\end{array}$

$\begin{array}{ll}8.6 \text { Exercises } & 128\end{array}$

9 Actuators 131

9.1 Electromagnetic actuators 131

9.2 Electrostatic actuators 140

9.3 Electro-optic devices 142

$\begin{array}{lll}9.4 & \text { Piezoelectric actuators } & 145\end{array}$

$\begin{array}{ll}9.5 \text { Exercises } & 145\end{array}$

10 Measurement Systems $\quad 147$

10.1 Solid-state transducers $\quad 147$

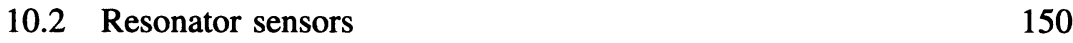

10.3 Optical fibre transducers 153

10.4 Pyrometry 162

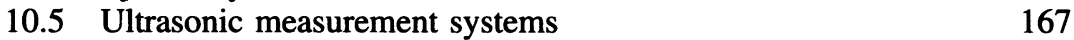

$\begin{array}{lll}10.6 & \text { Exercises } & 172\end{array}$

11 Digital Transducers and Interfacing $\quad 175$

$\begin{array}{ll}11.1 & 175 \\ 11.2 & 175\end{array}$

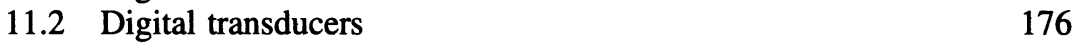

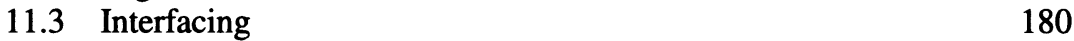

$\begin{array}{lll}11.4 & \text { Smart sensors } & 188\end{array}$

$\begin{array}{llr}11.5 & \text { Exercises } & 189\end{array}$

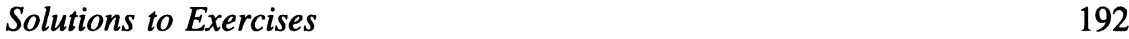

$\begin{array}{ll}\text { References and Bibliography } & 216\end{array}$

$\begin{array}{lr}\text { Index } & 219\end{array}$ 


\section{Preface}

Most quantities that we need to measure are inherently analogue. There is nothing very digital about a length or a temperature and although light may be considered to consist of photons most measurements involve such large numbers that the process is effectively analogue. Our own senses are analogue so it is hardly surprising to find that the vast majority of physical sensors are also analogue. It is only since the developments in microprocessor technology that digital transducers have become important, and have sometimes captured an undue proportion of attention; however, they still have to measure analogue quantities and most digital transducers therefore employ exactly the same physical principles as their analogue counterparts. This book discusses most of the transducers in current use, whether digital or analogue. The coverage is primarily from the measurand standpoint; for example, the different types of length transducer are discussed and compared together in one chapter, although we have also included chapters summarising the various transducer technologies, such as solid-state or fibre-optic devices. Digital transducers are dealt with in the same way, under length or temperature as appropriate, but a chapter is also devoted to their summary and classification.

The words 'sensor' and 'transducer' are widely used in referring to sensing devices, the former having gained in popularity in recent years. This is a pity because 'transducer' stresses the change in form of energy basic to the sensing process and leads to an elegant and powerful classification of devices. The word 'transducer' is used here when considering a complete sensing device, in which there is bound to be a change in form of energy; the word 'sensor' is reserved for devices which 'respond to a stimulus' but are not energy converting, such as a thermistor, which simply changes its resistance in response to temperature.

The most important transducer parameters are 'responsivity' and 'detectivity'; the former refers to the response of a transducer to the applied measurand and the latter to the least input measurand that can be detected. The use of these two separate words removes the ambiguity of the word 'sensitivity', unfortunately sometimes used in describing transducers, which may refer to the response either to the desired input or to an undesired input, or both together. These two responses must be distinguished and this is correctly accomplished by 'responsivity' and 'detectivity', which are used throughout the book.

The aim of the book is to provide an integrated account of the principles and 
properties of the most important types of physical transducer. The first chapter discusses the types of physical energy and the corresponding signals, and identifies the three basic types of transducers: self-generators, modulators and modifiers. A synthesis of the subject is attempted in chapter 2, describing the analogies that exist between different types of physical system and showing how our understanding can sometimes be improved by considering an analogy of a particular device or circuit. Chapter 3 starts with a three-dimensional representation of all possible transducers and goes on to consider the basic physical mechanisms available for transduction. Chapter 4 develops the relevant expressions for amplifiers and transducer bridges that are required before the detailed descriptions of the basic transducers for length, temperature and light are given in chapters 5,6 and 7. For each of these quantities the physical background and measurement standards are first explained, followed by both a theoretical treatment of the basic transducers and a description of their practical design and application. Chapter 8 includes the application of the basic transducers to several important fields of measurement, such as acceleration, force, pressure, flow and sound. Although transducers are usually thought of as input devices, output transducers are important in measurement systems, being usually referred to as 'actuators', and chapter 9 is devoted to the various types available. Chapter 10 is concerned with measurement systems, showing how transducers and actuators are used in complete systems, and including solid-state sensors, resonator sensors, optical fibre sensors, pyrometry and ultrasonics. The final chapter gives a summary and classification of digital transducers and an introduction to interfacing to computer systems. Many worked examples are given, together with a set of exercises at the end of each chapter, full solutions being provided at the end of the book.

The first edition of this book was devoted specifically to transducers and their characteristics, but in the second edition the authors have extended the coverage to include both instrumentation, in chapter 10 , and digital transducers and interfacing, in chapter 11. The book is therefore subtitled 'Characteristics, Applications, Instrumentation, Interfacing'. It is intended as a basic undergraduate text for students in engineering, physics and information technology. 


\section{Acknowledgements}

The authors wish to thank the former and present heads of the Cybernetics Department, Peter Fellgett and Kevin Warwick, for their encouragement and suggestions regarding the lecture courses on which the book is based, and Christine Usher who did much of the typing and corrections. They also acknowledge the feedback from the many Cybernetics and Engineering students who acted as willing guinea-pigs* during the development of the courses.

*Guinea-pigs are nocturnal animals that mostly sleep during the day. 